\title{
Un apéndice a los Triumphi de Petrarca: el Triumphus Fame IIa
}

\author{
José Luis QuEZADA A. \\ Universidad Nacional Autónoma de México
}

\begin{abstract}
Pese a la importancia de los Triumphi de Petrarca, aún no hay una edición crítica que ofrezca una versión definitiva del texto. En 1950, Roberto Weiss publicó por primera vez de forma íntegra este fragmento del Triumphus Fame; la reaparición de estos versos da cuenta de la incansable labor de revisión que Petrarca desarrollaba para la composición de sus obras. En los seis episodios que lo conforman, el aretino presenta un sinnúmero de personajes históricos y literarios, en gran parte de la antigüedad grecolatina. En esta "biblioteca ideal" petrarquesca, el Triumphus Fame revela el grado de conocimiento que Petrarca tenía de los autores clásicos ahí mencionados. Aquí se presenta la primera traducción al español del Triumphus Fame IIa.
\end{abstract}

Palabras clave: Triumphus Fame, antigüedad grecolatina, fragmento, terza rima, desfile triunfal.

Despite the importance of Petrarch's Triumphi, there is currently no critical edition that provides a definitive and uniform version. In 1950, Robert Weiss published this fragment in its complete form for the first time. With the re-discovery of these long-lost verses, Petrarch's dedication in revising and polishing his poems becomes evident. In the work's six episodes, a great number of historic and literary characters, mostly from Classical Antiquity, march through its pages. In this "ideal library", the Triumphus Fame shows the degree of knowledge Petrarch had of the classical authors he mentioned. This article offers the first translation into Spanish of the Triumphus Fame IIa.

KEYwords: Triumphus Fame, Classical Antiquity, fragment, terzarima, triumphal procession.

Con respecto al estudio de los Triumphi de Petrarca, queda todavía por escribirse una buena parte de la historia. La reconstrucción de este episodio literario sólo podrá realizarse completamente hasta que contemos con una edición definitiva del texto que pueda disipar todas las dudas que hasta ahora permanecen sin solución. No obstante, contamos con ediciones comentadas y anotadas de valor insustituible que significan 
un fundamento sólido para el estudio de esta obra. ${ }^{1}$ Además de esto, las investigaciones desarrolladas a lo largo del último siglo nos han permitido saber muchísimos aspectos antes desconocidos acerca de esta composición poética en terza rima. Baste un ejemplo: en contra de la versión que Petrarca mismo difundió afirmando que no había leído el sacro poema de Dante, versión que pervivió durante más de cinco siglos, ahora tenemos la certeza absoluta de que el poeta aretino no sólo leyó la Commedia, sino que también estudió e imitó deliberadamente el modelo dantesco. Numerosas pruebas de lo anterior pueden encontrarse en los Rerum vulgarium fragmenta, pero de manera más evidente en los Triumphi. ${ }^{2}$

Petrarca trabajó en este extenso poema en tercetos sobre todo en la segunda mitad de su vida; en esta obra asistimos a una sucesión de desfiles triunfales relacionados con los triumphi $i^{3}$ que los generales romanos encabezaban tras haber conseguido alguna victoria militar. La sucesión de estos desfiles se presenta de la siguiente manera: Triumphus Cupidinis, dividido en cuatro partes; Triumphus Pudicitie, Triumphus Fame, dividido en tres partes; Triumphus Temporis, y por último el Triumphus Eternitatis. En cada uno de estos episodios Petrarca presenta un sinnúmero de personajes tanto históricos como literarios, en su mayor parte personajes de la antigüedad grecolatina relacionados con los temas correspondientes a cada uno de los desfiles mencionados.

Si bien la mole de versos conservada permite hacernos una idea general acerca de la estructura ascendente, por así decir, que la obra presenta — desde el deseo hasta la eternidad - también es cierto que la lectura del poema hace evidente que éste carece de una revisión definitiva por parte del autor. Es bien sabido que el proceso de perfeccionamiento al que el poeta sometía sus obras era obsesivo y prolongado. En el caso de los Triumphi, la revisión se tornó interminable y el poema quedó finalmente inconcluso, igual que algunas otras de sus obras latinas, piénsese al menos en su otro gran proyecto poético: el Africa.

Ahora bien, el objetivo de esta contribución es ofrecer al lector una traducción al español de la que hace casi setenta años fue llamada por Roberto Weiss "la redazione sconosciuta di un capitolo del Trionfo della Fama" (1950). Este fragmento es indispensable para poder llevar a cabo un análisis completo de la obra. Como se mencionó antes, Petrarca dividió el Triumphus Fame en tres partes: en el caso de la segunda de

\footnotetext{
${ }^{1}$ Las ediciones consideradas para este trabajo que se enumeran en seguida de manera abreviada pueden consultarse en forma completa en la bibliografía compilada al final de este trabajo: V. Pacca (1996), E. Fenzi (1993), M. Ariani (1988), G. Ponte (1968), G. Martellotti (1951) y la traducción al español de G. M. Cappelli (2003).

${ }^{2}$ Con respecto a la imitación que Petrarca hace de Dante son muy útiles los estudios de Santagata, 1969: 163-211. Además no debe olvidarse la mutua dependencia que existe entre los Triumphi de Petrarca y el otro gran poema en tercetos del Trecento italiano, es decir la Amorosa visione de Giovanni Boccaccio, sobre lo cual pueden consultarse al menos Billanovich, 1956: 1-52, y Branca, 1959: 681-708.

${ }^{3}$ El término triumphus indica en latín tanto el triunfo mismo como el desfile militar que lo conmemoraba.

${ }^{4}$ Véase también E. H. Wilkins, "On Petrarch's Rewriting the Triumph of Fame", Speculum 39 (1964), 440-443, posteriormente publicado también en Wilkins, 1978: 293-297.
} 
ellas contamos con una redacción alterna transmitida por el manuscrito clasificado con la signatura Harleian 3264 del British Museum. Esta versión, de la que hasta antes del descubrimiento por parte de Weissse se conocían sólo los primeros nueve versos, es identificada actualmente por los estudiosos como Triumphus Fame IIa. La importancia de esta composición alterna reside ante todo —en palabras del propio Weiss - en que "oltre a rivelarci le intenzioni definitive del Petrarca circa uno dei capitoli più importanti dei Trionfi, la nuova redazione ci svela, assai più chiaramente che non la prima, ciò che potremmo chiamare la 'biblioteca ideale' del Petrarca, gli autori che studiava amorosamente e quelli che conosceva solo per fama, e che avrebbe bramato di leggere e possedere nella sua libreria" (Weiss, 1950: 39). En efecto, la "biblioteca ideale" contenida en el Triumphus Fame IIa nos revela el conocimiento, así como el desconocimiento que Petrarca tenía de los autores allí mencionados. A lo largo de este recorrido por el terreno de los autores clásicos, Petrarca presenta a filósofos, oradores, poetas e historiadores, tanto griegos como romanos. Este elenco de personajes está evidentemente ligado con la versión que podemos llamar definitiva del capítulo de los Triumphi, el Triumphus Fame II, así como con la égloga X del Bucolicum carmen petrarquesco, intitulada Laurea occidens (Petrarca, 1968), composición en la que también se presenta un catálogo de diversos personajes de la Antigüedad, en este caso exclusivamente poetas.

Después de que Weiss sacó nuevamente a la luz el texto alternativo, éste ha aparecido como apéndice en las ediciones más importantes de los Triumphi aparecidas después de 1950, sin embargo, en la traducción al español (Petrarca, 2003) con la que contamos, este apéndice no figura. Es ésta la razón que me ha llevado a proponer una versión del texto en cuestión, la primera en español de la que tengo noticia.

A continuación se presenta la versión bilingüe del Triumphus Fame IIa: la traducción que acompaña al texto es en prosa y está acompañada de algunas notas mínimas que buscan ofrecer al lector un apoyo para la mejor comprensión del texto. Para finalizar esta breve introducción, debe hacerse hincapié en la naturaleza fragmentaria del texto que aquí se presenta. En el Triumphus Fame IIa encontramos diversas lagunas y un grupo de versos independientes colocado al final y señalado como fragmento en la edición que he tomado como base. ${ }^{5}$

\section{Triumphus Fame IIa}

Poi che la bella e glorïosa donna così ornata giunse da man destra, volsimi a l'altra del suo onor colonna,

\footnotetext{
${ }^{5}$ Debido a que he considerado que es la más completa he seguido la siguiente edición: F. Petrarca, Trionfi, Rime estravaganti, codicedegliabbozzi, Vinicio Pacca et al. eds., Milán: Mondadori, 1996, y también he tenido a la vista en todo momento la edición de Weiss citada en la nota 4.
} 
e vidi a quella man gente silvestra, tacita e grave, che pensando avea fatto al ciel co l'ingegno alta fenestra.

Ivi vidi colui che pose idea ne la mente divina, e chi di questo e d'altre cose contendea ed era amico, ma a contender presto. Poi vidi il padre di filosofia Socrate, un vecchiarello allegro, onesto. Que' la trasse del cielo ove era pria ed allogolla in terra fra' mortali perché al vivere umano utile sia.

Poi vidi alcuni alzarsi ed aprir l'ali ove non bisognava ad ora ad ora, e far dal ciel nel fango brutti cali; Pittagora, che 'l nome il qual onora suoi possessor, se 'n dritta parte è preso, prima trovò; l'altra è tuba sonora, Senofonte; e Solon che diede a Creso il buon consiglio di guardare al fine, da molti udito ma da pochi inteso; e gli altri sei in non men pellegrine sedie vidi io, ma fama il ver non muta. Poi contendea Demostene ed Eschine: ciascun con sì tagliente e con sì aguta lingua ch'udendo lor querele tante Grecia mi parve sbigottita e muta. Senocrate, Anassagora e Cleante e Zenone e Ferecide, radice onde uscîr molte verdi e liete piante; ed Epicuro che col popol dice, purché 'l diletto sensual trabocchi un uom razional porco felice.

Poi colui ch'a se stesso tolse gli occhi perché 'l pensier la vista non occupe forse, o per non veder fiorir li sciocchi; e Crisippo a le cose oscure e cupe non men intento, e duo buon poverelli, l'un in un tino e l'altro in una rupe. Diogene e Parmenide son quelli di ch'io ragiono; Antistene, Anacarse, 
Crantor, Anassimene eran con elli;

Anassarco e Calan, che vivo s'arse

di viver sazio, e quel cui vaneggiando

Mongibello sepolcro onesto parse;

Varo e 'l gran Tullio che venian parlando

lingua latina, e Seneca il seguia;

e Virgilio ed Omero alto cantando.

Dolce mi fu il mirar lor leggiadria, in atto in lingue in abito distinta, ed udir lor celeste melodia.

Di lauro avea ciascun la fronte cinta, o d'edera o di mirto, altri ch'un solo che cantava canzon vera e non finta.

Euripide vid'io levarsi a volo e Sofoclè, duo nobili tragedi, [...]

e' Greci e' nostri, che son fatti eredi del monte diParnaso e per quei gioghi mosser più tardo, non men presti, i piedi.

Tal al parlar, tal riconobbi ai luoghi; quel era di Volterra e quel d'Aquino; ciascun par che suo sdegno in verso sfoghi.

Dinanzi a questo Orazio venusino con la sua lira e 'l fiorentin ch'è messo a cantar Pluto e Stilico e Ruffino.

Vidi Stazio a Virgilio ir sì da presso che li dava del pie' nelle calcagna e reverente umiliar se stesso.

Poi vidi con Lucan d'ultima Spagna Columela venir, A[...] e Marziale ch'un gran guascone aveva in lor compagna.

Non è l'ingegno né lo stile equale a la materia, onde di mille taccio, ma non posso tacer $[\ldots]$

Lucilio, Ennio, Pacuvio, Plauto ed Accio, Nevio; ed altri che poser in trastullo il mal d'amor, ricever fiamma e ghiaccio:

Anacreonte, Alceo e con Catullo, nodrito in Campo Marzo veronese, e Properzio ed Ovidio era e Tibullo. Ibico il grande amante calabrese iva con lor; fra ta' sette vidi una 
giovane greca assai bella e cortese d'amor lagnarsi e di sua ria fortuna. Poi vidi ond'ave appoggi ed elimenti nostra memoria fragile e digiuna.

Livio il gran padoan, da' fondamenti il qual di Roma così passo passo venne col tempo alle famose genti, era il primo fra questi e questi lasso parea del gran viaggio; e poi il secondo, Crispo Salustio che non parla in casso;

Trogo che col suo stile abbraccia il mondo, non stringe, e Iustin seco e Festo e Floro toccar la soperficie ma no 'l fondo;

Erodoto e Tucchidide e con loro Pollibio e Quinto Claudio, che tesseo di rozza trame un nobile lavoro; e in ciò sembiante il veritiero ebreo Iosefo ed Egisippo, in cinque libri che poi l'istoria sua più breve feo;

e Iulio Celso ch'io non so qual vibri meglio o 'l ferro o la penna; e Dare e Dite fra lor discordi e non è chi 'l ver cribri; così rimansi ancor l'antica lite di questi e d'altri e gli argomenti interi, ché le certe notizie son fallite.

Vidi ancor duo Corneli e duo Valeri, Orosio, Eutropio, Curzio ed altri molti tutti d'ingegno e d'eloquenzia alteri. $[\ldots]$

\section{[Frammento]}

Cinea e Carmadàs che di memoria vinsero ogni uomo, sì com Grecia afferma; Ortensio ch'à gran parte in questa gloria; Plinio con libri poi quattro e settanta di sua romana e naturale istoria. 


\section{Triumphus Fame IIa}

Después que la bella y gloriosa señora ${ }^{6}$ llegó por la derecha tan adornada, me volví hacia la otra columna de su honor y vi de aquel lado gente solitaria, silenciosa y solemne, que meditando había abierto una elevada ventana hacia el cielo con su ingenio. Ahí vi a aquel que colocó las ideas en la mente divina, y a quien sobre esto y sobre otras cosas contendía con él y era amigo, pero estaba dispuesto a $\operatorname{disputar}^{7}(10)$. Después vi al padre de la filosofía, Sócrates, un viejecillo alegre, digno de honor. ${ }^{8}$ Él la trajo del cielo donde primero estaba y la colocó en la tierra entre los mortales para que fuera útil a la vida humana. Después vi a algunos que de cuando en cuando abrían las alas y se elevaban hacia donde no debían y caían deshonrosamente del cielo en el fango: a Pitágoras, que fue el primero en encontrar el nombre que honra a quienes lo poseen, si es entendido correctamente (20). El otro es una tuba que resuena: Jenofonte; y Solón, que dio a Creso el buen consejo de mirar hacia el final, por muchos escuchado, pero por pocos entendido; y los otros seis ${ }^{9}$ en sillas no menos singulares vi yo, pero la fama no cambia la verdad. Después disputaban Demóstenes y Esquines, cada uno con un discurso tan impetuoso y penetrante que, escuchando sus encendidos encuentros, Grecia me parecía trastornada y muda (30). Jenócrates, Anaxágoras y Cleante y Zenón y Ferécides, raíz de donde surgieron muchas plantas verdes y vigorosas; y Epicuro que con el vulgo dice que un hombre racional es como un puerco feliz con tal de que el placer de los sentidos rebose. Luego vi a aquel que se arrancó a sí mismo los ojos, ${ }^{10}$ tal vez para que la vista no ocupara el pensamiento o bien para no ver prosperar a los tontos, y a Crisipo no menos interesado en los temas oscuros y tenebrosos (40), y a dos pobres buenos, uno en un barril y el otro en una roca. Diógenes y Parménides son aquellos de los que estoy razonando; Antístenes, Anacarsis, Crántor, Anaxímenes estaban con ellos; Anaxarco y Calán, ${ }^{11}$ que se arrojó al fuego harto de la vida, y aquel a quien en medio de su locura el Mongibelo ${ }^{12}$ pareció un honorable sepulcro. Vi a Varrón y al gran Tulio ${ }^{13}$ que llegaban hablando latín, y Séneca los seguía; (50) y Virgilio y Homero cantando cosas elevadas. Fue dulce para mí contemplar su elegancia, distinta en sus acciones, en su lengua, en su forma de ser, y oír su celeste melodía. Cada

${ }^{6}$ La "bella e glorïosa donna" es la Fama.

${ }^{7}$ Platón fue quien "pose idea en la mente divina" y su acompañante y contencioso amigo es Aristóteles.

${ }^{8}$ Sócrates encabeza el primer gran grupo de personajes antiguos conformado principalmente por filósofos y por algunos oradores, todos ellos griegos excepto en un par de casos.

${ }^{9}$ Solón y los otros seis son los llamados Siete sabios.

${ }^{10}$ Demócrito de Abdera.

${ }^{11}$ Filósofo hindú que formó parte del séquito de Alejandro Magno.

${ }^{12}$ El nombre Mongibelo, es decir, el Etna, está atestiguado en la poesía española de los Siglos de Oro. Véase, por ejemplo, el poema de Francisco de Quevedo, "Memoria inmortal de Don Pedro Girón, Duque de Osuna, muerto en la prisión", vv. 9-10: "En sus exequias encendió al Vesubio / Parténope, y Trinacria al Mongibelo" (1967: 18).

${ }^{13}$ Varrón y Cicerón están al frente de un segundo grupo de personajes donde tras ellos hay predominancia de poetas, la mayor parte latinos. 
uno de ellos tenía la frente ceñida de laurel o de hiedra o de mirto, ${ }^{14}$ excepto uno solo ${ }^{15}$ que cantaba una canción de verdad y no de ficción. Yo vi a Eurípides, ${ }^{16}$ que alzaba el vuelo y a Sófocles, dos nobles tragediógrafos, [...] Tanto griegos como hombres nuestros que fueron nombrados herederos del monte Parnaso y por aquellos parajes elevados se encaminaron tiempo después, pero no menos solícitamente. A alguno lo reconocí por su forma de hablar, a otro por su lugar de origen, aquél era de Volterra y éste de Aquino $;{ }^{17}$ cada uno parece desahogar su indignación en sus versos. Delante de ellos Horacio venusino con su lira y el florentino que se ocupó en cantar a Plutón, a Estilicón y a Rufino. ${ }^{18}$ Vi a Estacio seguir tan de cerca a Virgilio, (70) que con sus pasos le pisaba los talones, y humillarse reverentemente. Después vi venir de la lejana España con Lucano a Columela, A [... ] y a Marcial que tenía como compañero un gran gascón. ${ }^{19}$ $\mathrm{Ni}$ el ingenio ni el estilo están a la altura de la materia, por lo que no hablo de mil, pero no puedo no hablar de [...]. Lucilio, Ennio, Pacuvio y Accio, Nevio ${ }^{20}$ y otros que se burlaron (80) del mal de amor, que es soportar la llama y el hielo: Anacreonte, Alceo; y con Catulo, crecido en el campo Marte de Verona, y Propercio y Ovidio estaban y Tibulo. ${ }^{21}$ Íbico, el gran amante calabrés, iba con ellos; entre estos siete vi a una joven griega muy bella y cortés que se lamentaba del amor y de su triste fortuna. ${ }^{22}$ Después vi de dónde obtiene apoyo y alimento nuestra memoria que es frágil y defectuosa (90). Livio, ${ }^{23}$ el gran paduano, el cual desde la fundación de Roma fue avanzando paulatinamente hasta llegar a los más famosos personajes, era el primero entre ellos y aparecía cansado del largo viaje; y después el segundo, Crispo Salustio que no habla en vano; Trogo que con su estilo abraza el mundo, pero no lo abarca, y Justino con él y Festo y Floro, que tocaron la superficie, pero no el fondo. Herodoto y Tucídides y con ellos (100) Polibio y Quinto Claudio que tejió un noble trabajo con una áspera trama. Y en esto semejante el veraz judío Josefo y Egisipo, ${ }^{24}$ que después en cinco libros hizo su

\footnotetext{
${ }^{14}$ No es necesario abundar demasiado en la compleja simbología que asume el laurel en el universo petrarquesco, pero debe considerarse al menos la alusión a Laura, y a la gloria poética. En cuanto a la mención conjunta del laurel, la hiedra y el mirto véase F. Petrarca, Collatio laureationis XI, 1: "Nunc tamen et lauri mirtusque hedereque silentur", y Feo, 1987: 21.

${ }^{15}$ Para Petrarca, David, el poeta de los Salmos, es el único cuyo canto es verdadero en cuanto está dirigido a Dios.

${ }^{16}$ Para la alta estima que Petrarca sentía hacia Eurípides, véase Africa IX, 66-67.

${ }^{17}$ Aulo Persio Flaco y Décimo Junio Juvenal, poetas satíricos romanos.

${ }^{18}$ Claudio Claudiano que para Petrarca es florentino en realidad es originario de Alejandría. Las obras de Claudiano a que se alude con "Pluto e Stilico e Rufino" son respectivamente De raptu Proserpinae, De consulatu Stilichonis, In Rufinum.

${ }^{19}$ El poeta Décimo Magno Ausonio.

${ }^{20}$ Poetas latinos arcaicos de los que desde la época de Petrarca y hasta ahora se conservan pocos fragmentos.

${ }^{21}$ Un subgrupo de poetas, en este caso elegíacos.

${ }^{22}$ Esta joven griega que se lamenta es la poetisa Safo de Lesbos.

${ }^{23}$ Con la presentación de Tito Livio, Petrarca introduce un pequeño grupo de historiadores y analistas.

${ }^{24}$ En primer lugar se refiere al escritor judío Flavio Josefo y en segundo lugar también, aunque sin saberlo, ya que a este inexistente Egisippo se atribuía un resumen del Bellum Iudaicum de Josefo, pero el
} 
historia más breve; y Julio Celso ${ }^{25}$ que no sé qué maneje mejor, si la espada o la pluma. Y Dares y Dictis ${ }^{26}$ discordes entre sí, y no hay quien distinga la verdad. Así permanece todavía la antigua disputa de éstos y de otros y todos sus argumentos, (110) ya que las noticias certeras se han perdido. Vi todavía a dos $\operatorname{Cornelios}^{27}$ y a dos Valerios, a Orosio, Eutropio, Curcio y a muchos otros, todos orgullosos por su ingenio y elocuencia...

$[\text { Fragmento }]^{28}$

Cinea y Carmadas, ${ }^{29}$ que en cuanto a la memoria vencieron a todos los hombres, así como afirma Grecia; Hortensio, ${ }^{30}$ que tiene gran parte en esta gloria. Luego Plinio con setenta y cuatro libros de su historia natural y romana. ${ }^{31}$

\section{Obras citadas}

\section{I) Petrarca}

Petrarca, Francesco. 2003. Triunfos. Trad. Guido M. CAPPelli. Madrid: Cátedra. (Letras Universales, 345) 1996. Trionfi, Rime estravaganti, codice degli abbozzi. Ed. Vinicio PACCAY y Laura PAOLINO. Milán: Mondadori. (I Meridiani). Pp. 593-626. 1993. Il Canzoniere e i Trionfi. Ed. Enrico FenZI. Roma: Salerno. (I Diamanti). Pp. 807-811.

1988. Triumphi. Ed. Marco ARIANI. Milán: Mursia. (Grande universale Mursia). Pp. 433-447. 1968. Laurea occidens. Bucolicum carmen X. Roma: Edizioni di Storia e Letteratura. (Note e discussioni erudite, 12)

nombre Egisippo no es más que una deformación del nombre Iosippus. Véase Petrarca, 1996: 622, notas 103-105.

${ }^{25}$ Julio Celso Constantino, a quien durante la Edad Media se atribuían erróneamente los Commentarii de bello Gallico de Julio César.

${ }^{26}$ Autores respectivamente de las obras Historia de excidio Troiae y Ephemeris belli Troiani que fueron durante la Edad Media la única posibilidad de lectura acerca del ciclo troyano.

${ }^{27}$ Cornelio Nepote, autor del Liber de excellentibus ducibus exterarum gentium, y Cornelio Tácito, autor, entre otras obras, de las Historiae y los Annales.

${ }^{28}$ Este fragmento al que antes se aludió está separado en los manuscritos de los versos restantes y en dos de los testimonios está señalado con la nota "supra ubiocurret", que hace pensar en la posible incorporación del pasaje en algún punto del texto.

${ }^{29}$ Con respecto a estos personajes de memoria prodigiosa, veáse Cicerón, Tusculanae disputationes, I, 24, 59 .

${ }^{30} \mathrm{El}$ orador romano Quinto Hortensio Hórtalo.

${ }^{31}$ Cabe precisar que los libros que integran la Naturalis historia de Plinio son treinta y siete y no setenta y cuatro como afirma aquí Petrarca. 
1968. Opere di Petrarca. Ed. Giovanni PonTE. Milán: Mursia. (Le corone, 7). Pp. 325-328, 1057-1059.

1951. Rime, Trionfie Poesie Latine. Guido MarTellotTI et al. eds. Milán

/ Nápoles: Ricciardi. (La Letteratura italiana. Storia e testi 6). Pp. 481-578.

1950. Un inedito petrarchesco. La redazione sconosciuta di un capitolo del Trionfo della Fama. Ed. Roberto WeISS. Roma: Edizioni di Storia e Letteratura. (Raccolta di studi e testi, 29)

\section{Otros materiales citados}

Billanovich, Giuseppe, 1956. "Dalla Commedia e dall'Amorosa visione ai Trionfi”. Giornale Storico della Letteratura Italiana 123. Turín: Loescher. 1-52. Pp. 367-368.

Branca, Vittore. 1959. "Per la genesi dei Trionfi". La Rinascita 21, Florencia. Pp. 681-708.

De Quevedo y Villegas, Francisco. 1967. Obras completas, II (obras en verso). Ed. Felicidad BuENDÍA. Madrid: Aguilar.

FeO, Michele. 1987. "La prima corrispondenza poetica fra Rinaldo da Villafranca e Francesco Petrarca ritrovata e pubblicata da M. Feo". Quaderni petrarcheschi 4. Roma: Valerio Levi. Pp. 13-25.

GodI, Carlo. 1970. "La Collatio laureationis del Petrarca". Italia Medioevale e Umanistica 13. Padua: Antenore. Pp. 1-27.

SAntagatA, Marco. 1980."Dante in Petrarca". Giornale Storico della Letteratura Italiana 157. 499. Turín: Loescher. Pp. 445-452.

1969. "Presenze di Dante 'comico' nel Canzoniere del Petrarca". Giornale Storico della Letteratura Italiana, 146. Turín: Loescher. Pp. 163-211.

WeISS, Roberto. 1950. Un inedito petrarchesco. La redazione sconosciuta di un capitolo del "Trionfo della fama". Roma: Edizioni di Storia e Letteratura.

WiLKINS, Ernest Hatch. 1978. Studies on Petrarch and Boccaccio. Padua: Antenore. (Studi sul Petrarca, 6)

1964. "On Petrarch's Rewriting the Triumph of Fame", Speculum 39. Chicago: University of Chicago Press. Pp. 440-443. 